\title{
Sorangiadenosine, a New Sesquiterpene Adenoside from the Myxobacterium Sorangium cellulosum
}

\author{
Jong-Woong Ahn ${ }^{\dagger}$, Kyoung Hwa Jang ${ }^{\ddagger}$, Soon-Chun Chung ${ }^{\S}$, \\ Ki-Bong $\mathrm{Oh}^{\S} *$, and Jongheon $\mathrm{Shin}^{\ddagger *}$
}

\begin{abstract}
${ }^{\dagger}$ Division of Marine Environment and Bioscience, College of Ocean Science and Technology, Korea Maritime University, \#1 Dongsam, Youngdo, Busan 606-791, Korea; ${ }^{\ddagger}$ Natural Products Research Institute, College of Pharmacy, Seoul National University, \#28 Yungun, Jongro, Seoul 110-460, Korea; and ${ }^{\S}$ School of Agricultural Biotechnology, Seoul National University, San 56-1, Sillim, Gwanak, Seoul 151-921, Korea
\end{abstract}

shinj@snu.ac.kr

\section{Contents}

General Experimental Method $\quad$ S2

$\begin{array}{ll}\text { Analytical data of Sorangiadenosine } & \text { S3 }\end{array}$

The ${ }^{1} \mathrm{H}$ NMR spectrum of of Sorangiadenosine in DMSO- $\boldsymbol{d}_{6} \quad$ S4

The ${ }^{13} \mathrm{C}$ NMR spectrum of of Sorangiadenosine in DMSO- $\boldsymbol{d}_{6} \quad$ S5

The HSQC NMR spectrum of of Sorangiadenosine in DMSO- $\boldsymbol{d}_{6} \quad$ S6

The COSY NMR spectrum of of Sorangiadenosine in DMSO- $\boldsymbol{d}_{6} \quad$ S7

The HMBC spectrum of of Sorangiadenosine in DMSO- $\boldsymbol{d}_{6} \quad$ S8

The NOESY spectrum of of Sorangiadenosine in DMSO- $\boldsymbol{d}_{6} \quad$ S9 


\section{General Experimental Method.}

Fermentation. The slant culture of JW484 was cultivated in 2 L Erlenmeyer flasks containing $400 \mathrm{~mL}$ of a medium consisting of potato starch $0.8 \%$, glucose $0.2 \%$, soyameal $0.1 \%, \mathrm{MgSO}_{4} \cdot 7 \mathrm{H}_{2} \mathrm{O} \quad 0.1 \%, \mathrm{CaCl}_{2} \cdot 2 \mathrm{H}_{2} \mathrm{O} \quad 0.1 \%$, EDTA Fe(III)- $\mathrm{Na}^{+}$salt $0.0008 \%$ and XAD-16 1.5\% (w/v) in distilled water. Also added to the medium was XAD-16 $(1.5 \% \mathrm{w} / \mathrm{v})$ for the enhancement of metabolite production. Prior to autoclaving, the $\mathrm{pH}$ of the medium was adjusted to 7.2 with $\mathrm{KOH}$. The flasks were incubated at 30 ${ }^{\circ} \mathrm{C}$ for 10 days on a rotary shaker at $160 \mathrm{rpm}$.

Extraction and Isolation. At the end of fermentation (20 L), wet cell mass and adsorbent resin XAD-16 were harvested by centrifugation and extracted with acetone (1 $\mathrm{Lx} 3$ ). The aqueous layer, after removal of acetone under vacuum, was adjusted to $\mathrm{pH} 7$ by $\mathrm{KOH}$ and twice extracted with EtOAc $(1 \mathrm{~L} \mathrm{x} 2)$. The organic solution was dried with $\mathrm{Na}_{2} \mathrm{SO}_{4}$ and the solvent evaporated under vacuum. The brown residue was separated between $15 \%$ aqueous $\mathrm{MeOH}$ and $n$-hextane. The aqueous $\mathrm{MeOH}$ layer (670 mg) was directly separated by $\mathrm{C}_{18}$ reversed-phase HPLC (YMC ODS-A column, $20 \%$ aqueous $\mathrm{MeOH})$ to afford pure compound $\mathbf{1}$ as a pale yellow gum $(28.4 \mathrm{mg})$. 


\section{Analytical data of compound 1}

Sorangiadenosine (1): colorless gum, $[\alpha]^{20}-78.7^{\circ}(c$ 1.17, $\mathrm{MeOH}) ; \mathrm{IR}(\mathrm{NaCl})$ $v_{\max } 3400$ (br), 2920, 1610, 1530, $1475 \mathrm{~cm}^{-1}$; UV (MeOH) $\lambda_{\max }(\log \varepsilon) 213$ (4.81), 265 (3.97) nm; ${ }^{1} \mathrm{H}$ NMR (DMSO- $\left.d_{6}\right) \delta 0.96(\mathrm{~s}, 3 \mathrm{H}), 1.28(\mathrm{~m}, 1 \mathrm{H}), 1.31(\mathrm{~m}, 1 \mathrm{H}), 1.33(\mathrm{~m}$, 1H), $1.39(\mathrm{~s}, 3 \mathrm{H}), 1.40(\mathrm{~m}, 1 \mathrm{H}) \times 2,1.49(\mathrm{~m}, 1 \mathrm{H}), 1.51(\mathrm{~m}, 1 \mathrm{H}), 1.54(\mathrm{~m}, 1 \mathrm{H}), 1.57(\mathrm{~m}$, 1H), 1.59 (br d, 1H), 1.64 (s, 3H), 1.89 (br dd, 1H), 2.05 (br d, 1H), 2.36 (ddd, 1H), 2.48 (dd, 1H), $3.54(\mathrm{dd}, 1 \mathrm{H}), 3.67(\mathrm{dd}, 1 \mathrm{H}), 3.95(\mathrm{dt}, 1 \mathrm{H}), 4.15(\mathrm{dd}, 1 \mathrm{H}), 4.61$ (br s, 1H), 4.66 (br s, 1H), $5.34(\mathrm{dd}, 1 \mathrm{H}), 5.86(\mathrm{~d}, 1 \mathrm{H}), 6.28\left(\right.$ br s, NH), $8.21(\mathrm{~s}, 1 \mathrm{H}), 8.34(\mathrm{~s}, 1 \mathrm{H}){ }^{13} \mathrm{C}$ NMR (DMSO- $\left.d_{6}\right) 18.8,19.2,20.5,20.6,26.0,26.7,34.2,36.7,40.3,44.8,45.5,47.7$, $57.8,61.6,70.6,73.4,85.8,88.0,108.5,120.3,139.6,148.0,149.9,151.5,154.3$, ; HRFABMS $m / z$ 472.2922 $[\mathrm{M}+\mathrm{H}]^{+}$(calcd for $\left.\mathrm{C}_{25} \mathrm{H}_{38} \mathrm{~N}_{5} \mathrm{O}_{4}, 472.2924\right)$. 

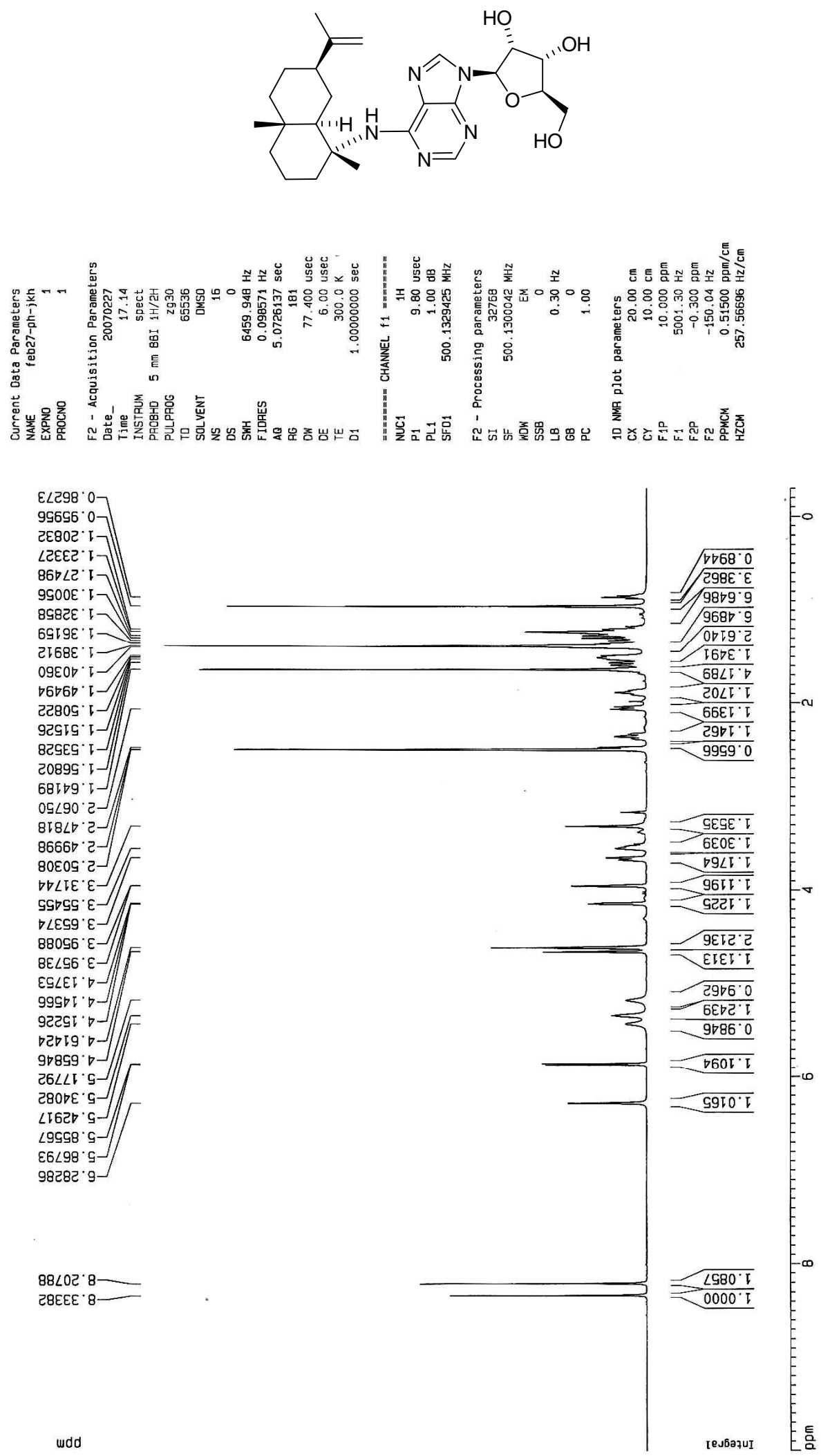

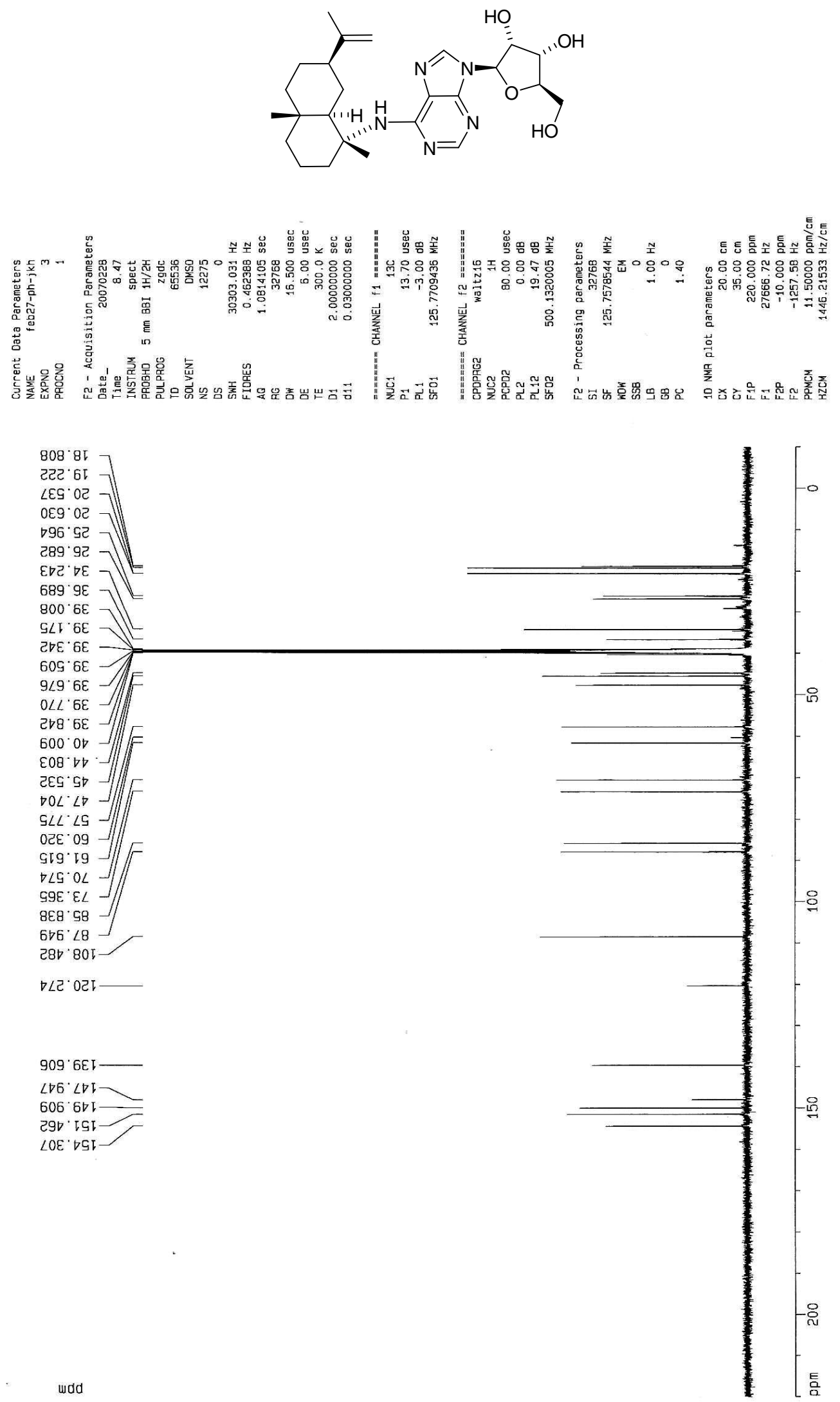


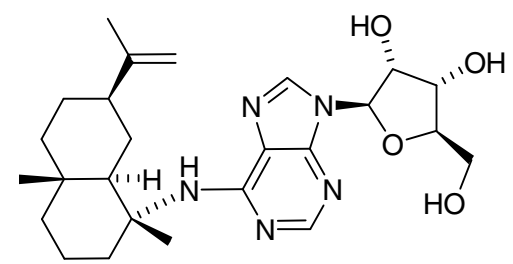

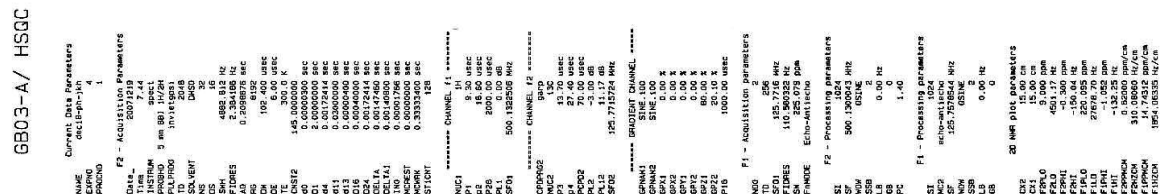

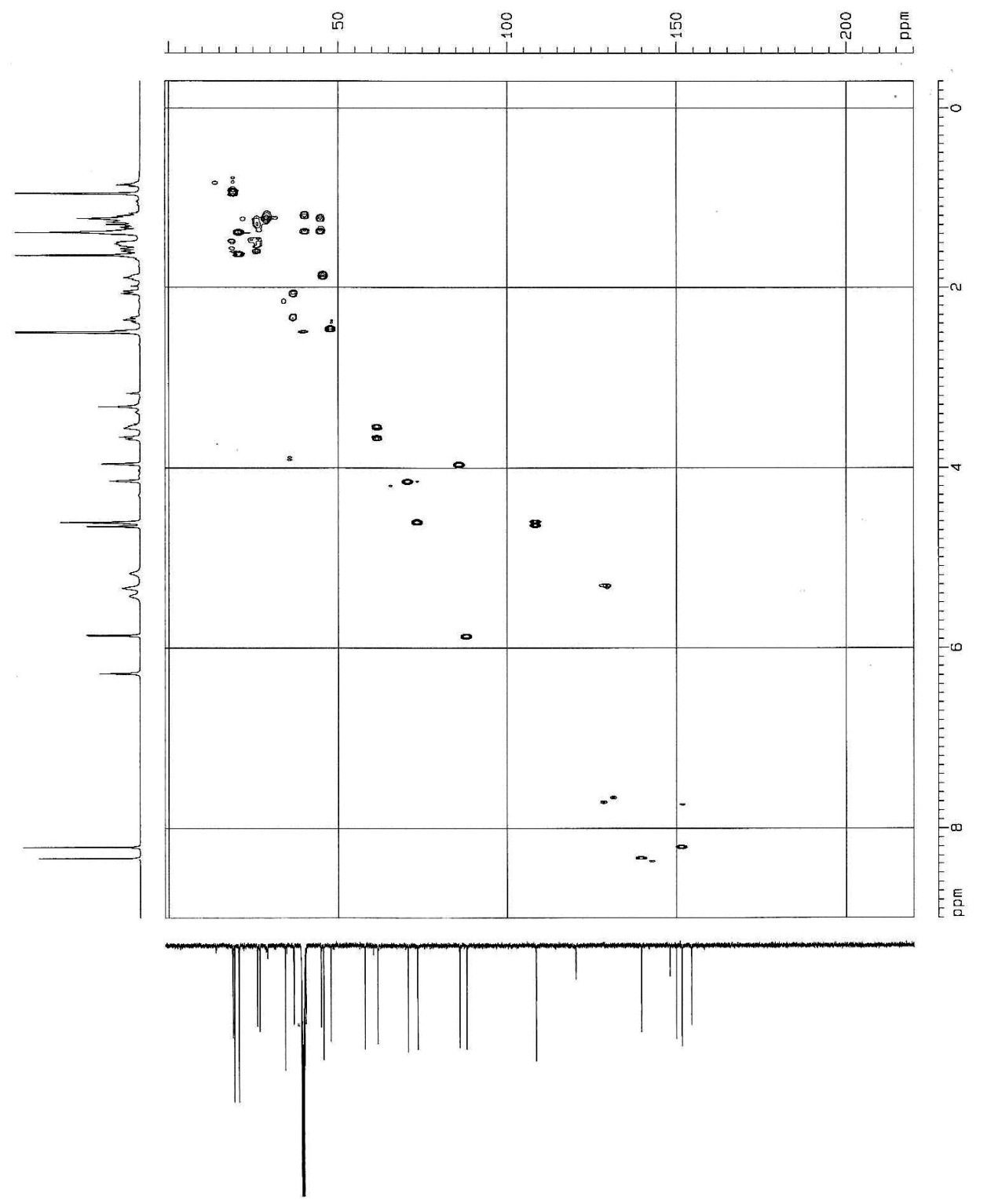

The HSQC Spectrum of Sorangiadenosine (compound 1) in DMSO- $d_{6}$ 

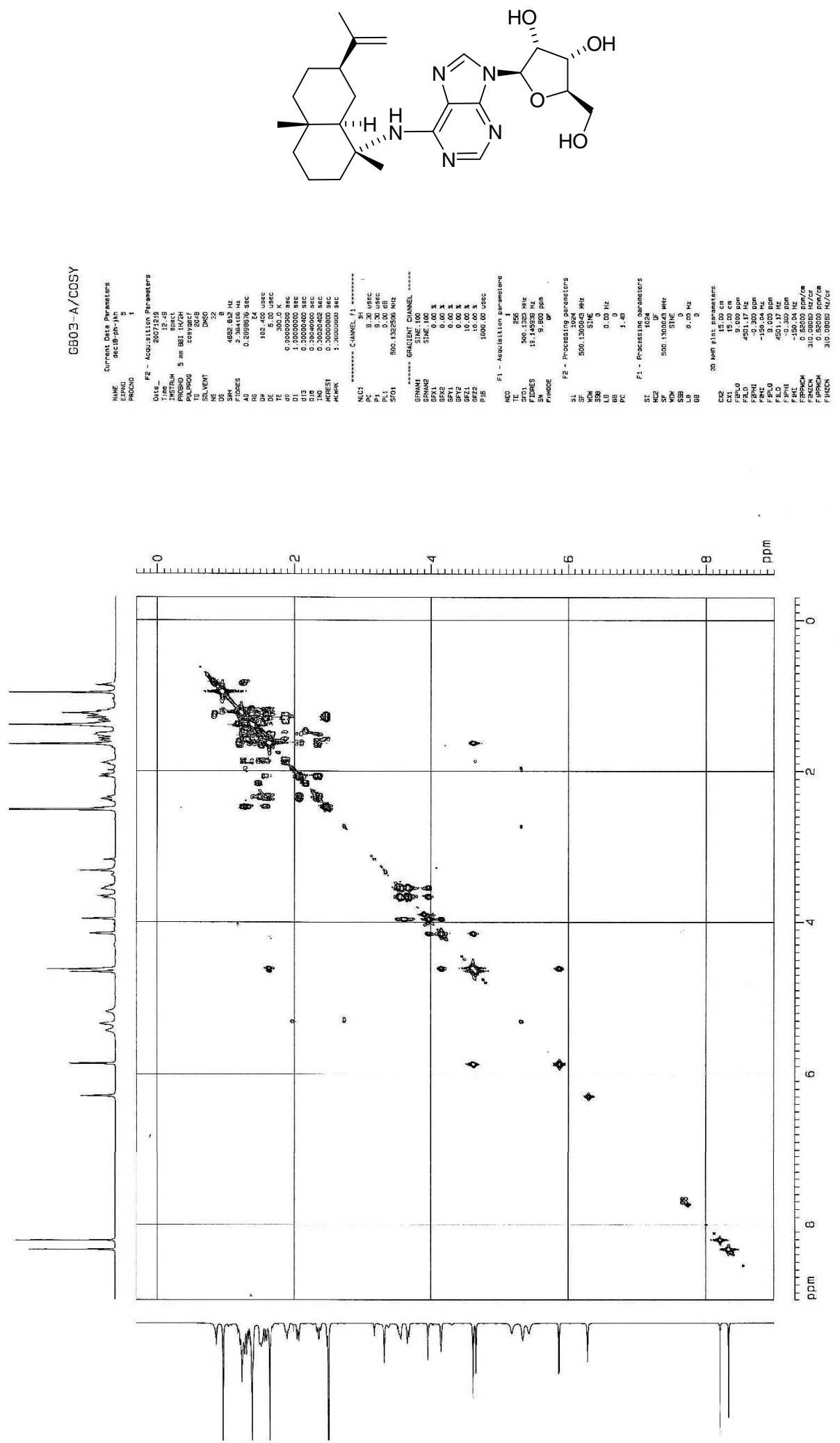

The COSY Spectrum of Sorangiadenosine (compound 1) in DMSO- $d_{6}$ 

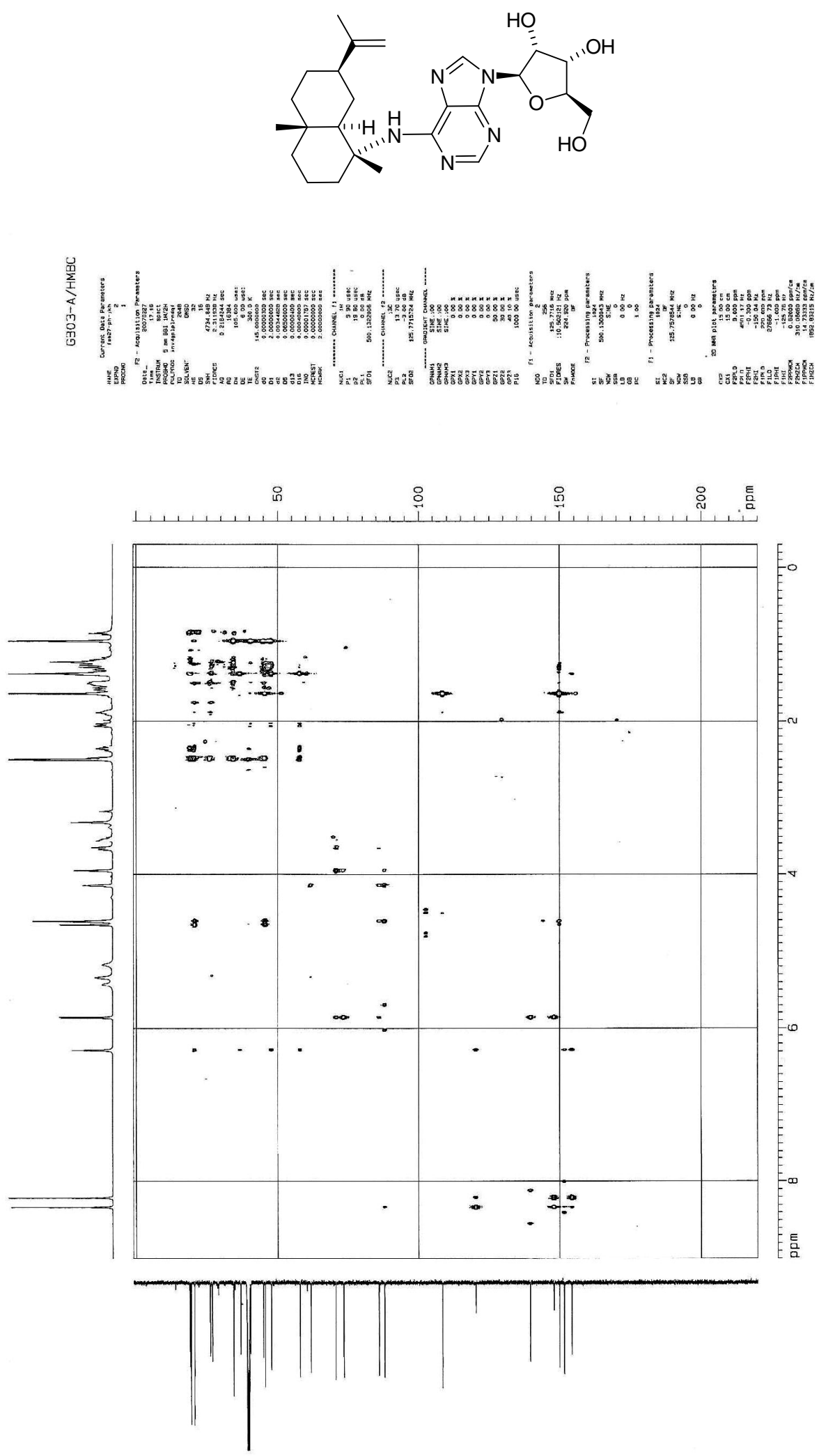

The HMBC Spectrum of Sorangiadenosine (compound 1) in DMSO- $d_{6}$ 

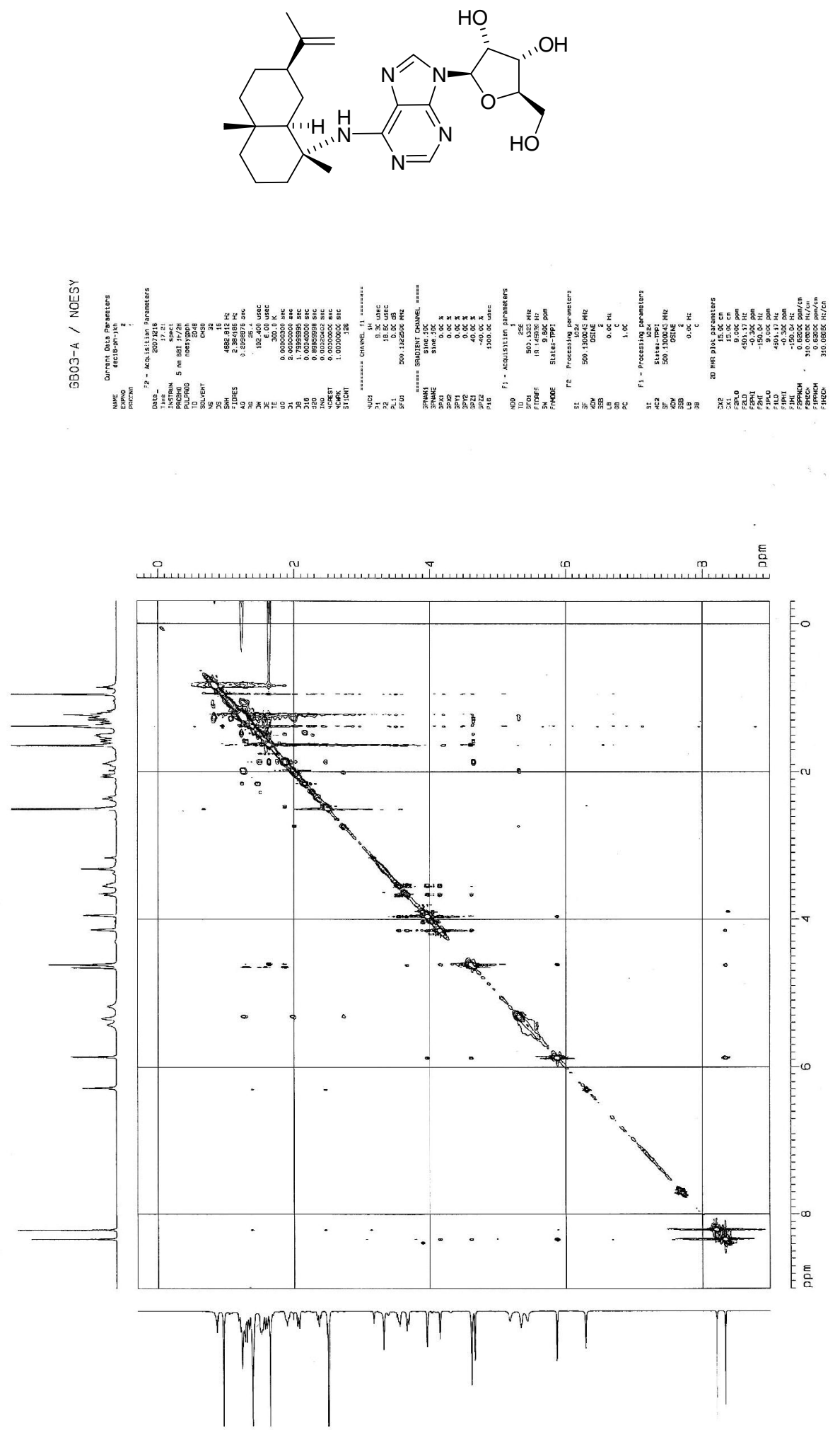

The NOESY Spectrum of Sorangiadenosine (compound 1) in DMSO- $d_{6}$ 